\section{Menopause and Possible Effect on Association Between Age and Anticyclic Citrullinated Peptide Antibodies in Women At Risk of Rheumatoid Arthritis}

\section{To the Editor:}

We read with interest the article by Berens, et $a l^{1}$ reporting that increasing age was associated with positivity for anticyclic citrullinated peptide antibodies (anti-CCP) 3.1 and anti-CCP-IgA in individuals at risk of rheumatoid arthritis (RA), that is, first-degree relatives (FDR) of patients with RA. We found similar results in a Swiss cohort of FDR: anticitrullinated protein antibodies (ACPA) positivity, particularly anti-CCP3.1, was associated with older age ${ }^{2}$. However, in contrast to Berens, et al $^{1}$, we found a peak in prevalence in the age group of 45 to 55 years, particularly among women. While the number of ACPA-positive men was too low to make definite inferences about a differential effect between male and females, our findings are in line with the peak of incidence of RA during the fifth decade of life, around the age at menopause in women ${ }^{3}$. In addition, in a subsequent study, we found that the early postmenopausal period, during the first 6 years after menopause, was most strongly associated with ACPA positivity ${ }^{4}$. After stratifying by menopausal status, in pre- and postmenopausal women, we no longer found an effect of age, suggesting that ACPA positivity was associated with being postmenopausal and not with age per se. Our results suggested that the acute decline in ovarian function could favor the development of autoimmunity associated with RA, which eventually may contribute to the increased risk of developing RA in women.

These findings are consistent with studies that have reported that the postmenopausal period, an early age at menopause, the postpartum period, and treatment with antiestrogen agents were associated with RA onset ${ }^{5,6,7}$. All these phenomena have in common an acute decline in estrogen bioavailability. Some mechanistic explanations for the increased risk of RA in conditions with low estrogen have been presented, such as the increase in proinflammatory cytokines and a proinflammatory state in menopause characterized by low IgG sialylation and increase in agalactosylated IgG glycans ${ }^{8,9,10}$. Agalactosylated proinflammatory IgG glycans decrease after the administration of conjugated estrogens, and estrogen treatment significantly increases sialylation in postmenopausal women ${ }^{9,10}$.

We agree with Berens, et al that increasing age should be considered in the interpretation of anti-CCP3.1 positivity in individuals at risk for RA; however, we wonder whether the association with age may be confounded by the effect of menopause. As preventive interventions for RA are being developed, we stress the importance of future studies to establish the predictive performance of anti-CCP3.1 positivity, taking into account other biomarkers and subject characteristics, to identify individuals at high risk of developing RA. Among other individual characteristics, we suggest that the postmenopausal period, and particularly the first years after menopause, may constitute a factor that should be taken into account in female FDR when considering screening for RA.

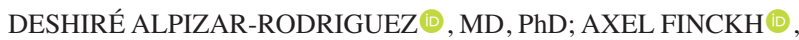
MD, Professor, Division of Rheumatology, Geneva University Hospital, Geneva, Switzerland. Address correspondence to Dr. D.

Alpizar-Rodriguez, Geneva University Hospital, 26 Ave. Beau-Séjour, 1211 Geneva, Switzerland.E-mail: deshire_alpizar@hotmail.com, Axel.Finckh@hcuge.ch

\section{REFERENCES}

1. Berens HM, Polinski KJ, Mikuls TR, Khatter S, August J, Visser A, et al. Anti-CCP3.1 and anti-CCP-IgA are associated with increasing age in individuals without rheumatoid arthritis. J Rheumatol 2019;46:1556-9.

2. Alpizar-Rodriguez D, Brulhart L, Mueller RB, Moller B, Dudler J, Ciurea A, et al. The prevalence of anticitrullinated protein antibodies increases with age in healthy individuals at risk for rheumatoid arthritis. Clin Rheumatol 2017;36:677-82.

3. Kvien TK, Uhlig T, Odegard S, Heiberg MS. Epidemiological aspects of rheumatoid arthritis: the sex ratio. Ann N Y Acad Sci 2006;1069:212-22.

4. Alpizar-Rodriguez D, Mueller RB, Moller B, Dudler J, Ciurea A, Zufferey $\mathrm{P}$, et al. Female hormonal factors and the development of anti-citrullinated protein antibodies in women at risk of rheumatoid arthritis. Rheumatology 2017;56:1579-85.

5. Bengtsson C, Malspeis S, Orellana C, Sparks JA, Costenbader KH, Karlson EW. Association between menopausal factors and the risk of seronegative and seropositive rheumatoid arthritis: results from the Nurses' Health Studies. Arthritis Care Res 2017;69:1676-84.

6. Peschken CA, Robinson DB, Hitchon CA, Smolik I, Hart D, Bernstein CN, et al. Pregnancy and the risk of rheumatoid arthritis in a highly predisposed North American Native population. J Rheumatol 2012;39:2253-60.

7. Caprioli M, Carrara G, Sakellariou G, Silvagni E, Scire CA. Influence of aromatase inhibitors therapy on the occurrence of rheumatoid arthritis in women with breast cancer: results from a large population-based study of the Italian Society for Rheumatology. RMD Open 2017;3:e00523.

8. Pfeilschifter J, Koditz R, Pfohl M, Schatz H. Changes in proinflammatory cytokine activity after menopause. Endocr Rev 2002;23:90-119.

9. Ercan A, Kohrt WM, Cui J, Deane KD, Pezer M, Yu EW, et al. Estrogens regulate glycosylation of IgG in women and men. JCI Insight 2017;2:e89703.

10. Engdahl C, Bondt A, Harre U, Raufer J, Pfeifle R, Camponeschi A, et al. Estrogen induces St6gal1 expression and increases IgG sialylation in mice and patients with rheumatoid arthritis: a potential explanation for the increased risk of rheumatoid arthritis in postmenopausal women. Arthritis Res Ther 2018;20:84.

First Release December 1 2019; J Rheumatol 2020;47:2; doi:10.3899/jrheum.190836 